CASSOWARY volume I (1): 103 - 120

ISSN : 2614-8900

E-ISSN : 2622-6545

CProgram Pascasarjana Universitas Papua, https://pasca.unipa.ac.id/

\title{
Perubahan kondisi biofisik-kimia lahan akibat pembangunan kanal pada areal IUPHHBK-HA (Sagu) PT. Austindo Nusantara Jaya Agri Papua di Kabupaten Sorong Selatan
}

\author{
Changes In Land Biophysical-Chemical Conditions Due to the Construction of Canals \\ on IUPHHBK-HA (Sago) PT. Austindo Nusantara Jaya Agri Papua on South Sorong \\ Regency
}

Reynold Kesaulija, Nurhaida Sinaga, Max J. Tokede

Program Studi Ilmu Lingkungan, Universitas Papua

Jalan Gunung Salju Amban, Manokwari, Papua Barat, Indonesia

\begin{abstract}
The constructions of canals for water use and management as well as supporting activities of productions, transportation and firebreaks lines are expected to have an impact on the biophysical and chemical changes in construction land. Therefore, the aims of this research are to know the amount of vegetation lost due to land clearing for canal constructions, land biophysical-chemical conditions changed as a result of canal clearing, aboveground carbon dioxide estimation and soil carbon stock estimation. Primary data collection determined by purposive on canal line for stand structure and composition, along with soil carbon estimation. The results showed that the opening of canal area of 82,35 ha will result in the loss of 19.866 sago trees on $40 \mathrm{~cm}$ average in diameter and 3.642 mature trees. Thus, sago starch on 82,35 ha will lost as much as 637,27 tons or $637.265,48 \mathrm{~kg}$. Changes in land biophysical-chemical due to canal constructions are habitat fragmentation, increase in soil erosion, land slide of canal wall, changes in water quality particularly solid suspension total as a direct impact to increased turbidity, sedimentation, and siltation of canals. Furthermore, the impact of 82,35 ha canal construction was increasing of carbon dioxide $\left(\mathrm{CO}_{2}\right)$ emission as much as 38.716,48 ton, and it is estimated that it will increase in line with future canal construction. Based on soil bulk density ranging from 0,58 to $1.22 \mathrm{~g} / \mathrm{cm}_{3}$ and Carbon-organic content ranging from 16.65 to $54,16 \%$, it is estimated that carbon stock on 0 to $30 \mathrm{~cm}$ soil layer on $1 \mathrm{Ha}$ area will be lost as 109 ton.
\end{abstract}

Keywords: change, canal, Biophisical-chemical, Sorong Selatan

ABSTRAK: Pembangunan kanal untuk pemanfaatan dan pengelolaan air serta penunjang aktifitas produksi, transportasi dan jalur sekat bakar diduga akan berdampak terhadap perubahan biofisik dan kimia lahan pada areal konstruksi. Oleh sebab itu penelitian ini dilakukan dengan tujuan untuk mengetahui jumlah tanaman (vegetasi) yang hilang akibat pembukaan areal untuk kontruksi kanal, mengetahui perubahan biofisik-kimia lahan yang ditimbulkan akibat pembukaan kanal, mengetahui dugaan jumlah emisi karbon dioksida permukaan, dan dugaan cadangan karbon (carbon stock) dalam tanah. Pengumpulan data primer dilakukan pada titik sampling yang telah ditentukan secara purposif atau sengaja pada jalur kanal dan pengambilan data 
komposisi dan struktur tegakan serta pendugaan karbon di dalam tanah. Hasil penelitian menunjukan pohon sagu berdiameter rata-rata $40 \mathrm{~cm}$ yang hilang akibat pembukaan kanal seluas 82.35 Ha sebanyak 19.866 pohon dan yang telah masak tebang sebanyak 3.642 pohon, sehingga pati sagu yang hilang dengan luasan $82.35 \mathrm{Ha}$ sebanyak 637.27 ton atau $637,265.48 \mathrm{Kg}$. Perubahan biofisik-kimia lahan yang diakibatkan pada pembangunan kanal yaitu fragmentasi habitat, meningkatkan erosi dan longsoran pada dinding kanal, perubahan kualitas air terutama meningkatnya Total Padatan Tersuspensi (TSS) yang berdampak langsung meningkatnya kekeruhan, sendimentasi dan pendangkalan kanal. Selanjutnya penambahan jumlah emisi karbon dioksida (CO2) sebesar 38,716.48 Ton $\mathrm{CO} 2$ pada luasan $82.35 \mathrm{Ha}$ dan diduga akan meningkat sejalan dengan peningkatan luas konstruksi kanal. Berdasarkan bobot isi (bulk desity) tanah yang berkisar antara $0.58-1.22 \mathrm{~g} / \mathrm{cm} 3$ dan kandungan COrganik yang berkisar antara $16.65-54.16 \%$, diduga cadangan karbon pada lapisan 0 $-30 \mathrm{~cm}$ seluas 1 ha akan hilang sebesar 109 ton.

Kata Kunci: perubahan, kanal, biofisika-kimia, Sorong Selatan

\section{PENDAHULUAN}

Indonesia merupakan negara yang terletak di daerah tropika basah yang kaya akan tanaman penghasil karbohidrat dan mampu menjadi sumber karbohidrat terbesar di dunia. Indonesia dalam mencukupi kebutuhan karbohidrat sangat bertumpu pada komoditas padi. Rendah dan sulitnya meningkatkan produktivitas padi disebabkan oleh banyaknya faktor internal dan eksternal yang mengganggu. Untuk mengatasi kekurangan pangan dan pemenuhan karbohidrat maka perlu pemanfaatan tanaman karbohidrat selain dari bijibijian, salah satunya adalah tanaman sagu (Metroxylon Spp.).

Luas hutan sagu di Papua diperkirakan mencapai 980.000 ha dan kebun sagu 14.000 ha yang tersebar pada beberapa daerah yaitu Salawati, Teminabuan (Sorong Selatan), Bintuni, Mimika, Merauke Wasior, Serui, Waropen, Mamberamo, Sarmi dan Sentani (Flach, 1983 dalam Kanro. et al., 2003). Kanro. et al., (2003) juga menyatakan sagu mempunyai peranan sosial, ekonomi dan budaya yang cukup penting di Papua karena merupakan bahan maka- nan pokok bagi masyarakat terutama yang bermukim di daerah pesisir.

Hasil Interpretasi Citra Lansat ETM7 tahun 2006 yang dilakukan oleh Laboratorium Sistem Informasi Geografi Fakultas Kehutanan Universitas Negeri Papua memperkirakan luas hutan sagu di Provinsi Papua Barat seluas 601.471,69 Ha yang dibagi berdasarkan fungsi kawasan hutan yang tersebar di 5 kabupaten, dengan pembagian kerapatan tinggi dan rendah. Dimana persebaran sagu terluas berada di Kabupaten Sorong Selatan yang memiliki hutan sagu seluas 249.628,85 ha yang disusul oleh kabupaten Teluk Bintuni dengan luas hutan sagu 199.843.09 ha, sedangkan Kabupaten Sorong seluas 78.534,67 ha dan Kabupaten Kaimana seluas 67.312 ha, dan hutan sagu terkecil berada di kabupaten Teluk Wondama dengan luasan 6.152,24 Ha.

Prihatman (2000) menjelaskan beberapa manfaat sagu antara lain (a). pelepahnya dipakai sebagai dinding rumah atau pagar rumah, (b). daunnya untuk atap, (c). kulit atau batangnya merupakan kayu bakar yang bagus, (d). aci sagu (bubuk yang dihasilkan dengan cara mengekstrasi pati dari umbi atau 
empulur batang) dapat diolah menjadi berbagai makanan. (e). sebagai makanan ternak, (f). serat sagu dapat dibuat hardboard atau bricket bangunan bila dicampur semen, (g). dapat dijadikan perekat (lem) untuk kayu lapis, (h). apabila rantai glukosa dipotong menjadi 35 rantai glukosa (modifief starch) dapat dipakai menguatkan daya adhesive dari proses pewarnaan kain pada industri tekstil, dan (i).dapat diolah menjadi bahan bakar methanol-bensin.

Menjaga dan meningkatkan produktifitas tanaman sagu, dibutuhkan kanal (parit besar). Karena tanaman ini membutuhkan air yang cukup selama umur pertumbuhan. Tanaman sagu ini memiliki ketergantungan yang tinggi terhadap air, karena itu pembuatan kanal dalam mengatur kondisi habitat sangat dibutuhkan. "Kanal menjadi solusi untuk mempertahankan kecukupan air pada musim kemarau terutama pada lahan gambut yang menjadi habitat sagu.

Kanal selain berfungsi untuk mengatur tata air sekaligus sebagai sarana transportasi batang (tual) sagu yang dipanen. Perancangan kanal harus juga dapat memperlancar proses pengangkutan batang (tual) sagu yang dipanen ke pabrik dapat berjalan lancar guna memenuhui bahan baku per hari. Namun pembangunan kanal yang tidak terencana dengan baik justru dapat menyebabkan dampak negatif terhadap kondisi biofisik dan kimia lahan habitat sagu.

PT. Austindo Nusantara Jaya Agri Papua merupakan Perusahaan Badan Usaha Milik Swasta (BUMS) dengan Status Penanaman Modal Asing (PMA) yang berinvestasi pengolahan hutan sagu alam dalam bentuk Izin Usaha Pemanfaatan Hasil Hutan Bukan Kayu pada Hutan Alam (IUPHHBKHA) dari Pemerintah Kabupaten Sorong Selatan dengan Surat Keputusan Bupati Sorong Selatan Nomor 86 tahun 2010 tanggal 12 Mei 2010, dengan luas areal konsesi $40.000 \mathrm{Ha}$ dengan jangka waktu 25 tahun. Untuk usaha operasional usaha penebangan sagu tersebut, salah satu teknologi pembukaan lahan yang dilakukan adalah pembangunan kanal-kanal pada blok-blok tebangan. Apakah pembangunan kanal yang dilakukan oleh PT. Austindo Nusantara Jaya Agri Papua oleh usaha pemu-ngutan sagu akan memberikan perubahan terhadap kondisi biofisik dan kimia lingkungan disekitarnya menjadi masalah yang akan dijawab dalam penelitian ini.

Tujuan penelitian ini adalah 1) Mengetahui jumlah tanaman (vegetasi) yang hilang akibat pembukaan areal untuk kontruksi kanal pada areal konsesi PT. Austindo Nusantara Jaya Agri Papua2) Mengetahui perubahan biofisik-kimia lahan yang ditimbulkan akibat pembukaan kanal pada areal konsesi PT. Austindo Nusantara Jaya Agri Papua. 3) Mengetahui prediksi jumlah emisi karbon di atas permukaan yang dilepas ke udara akibat penebangan hutan oleh aktivitas pembukaan kanal pada areal konsesi PT. Austindo Nusantara Jaya Agri Papua. 4) Mengetahui dugaan cadangan karbon (carbon stock) dalam tanah (dibawah permukaan) pada areal konsesi PT. Austindo Nusantara Jaya Agri Papua.

Kegunaan dari penelitian ini adalah1) Sumbangan bagi ilmu lingkungan khususnya mengenai dampak yang ditimbulkan oleh aktivitas pembukaan kanal pada areal konsesi pada areal konsesi PT. Austindo Nusantara Jaya Agri Papua, 2) Dasar pengambilan kebijakan bagi Pemerintah Kabupaten Sorong Selatan dalam menentukan program dan kegiatan yang berkaitan dengan monitoring dan evaluasi pelaksanaan Ijin Usaha Pemanfaatan Hasil Hutan Bukan Kayu (Sagu) pada Hutan Alam PT. Austindo Nusantara 
Jaya Agri Papua dalam upaya pengendalian dampak lingkungan. 3) Sebagai referensi bagi penelitian selanjutnya.

\section{METODE PENELITIAN}

Penelitian dilakukan pada bulan Juli 2013 di Areal Konsesi IUPHHBKHA (Sagu) PT. Austindo Nusantara Jaya Agri Papua di Kabupaten Sorong Selatan. Untuk Titik Pengamatan dilakukan ada Boundary Kanal, Kanal Primer, pada Kanal Sekunder yang terdapat dalam areal Konsesi IUPHH BK-HA (Sagu) PT. Austindo Nusantara Jaya Agri Papua.

Alat yang digunakan dalam penelitian ini adalah tallysheet, meter roll, kompas, clinometer, turbidimeter, secci disk, termometer air, GPS Garmin OREGON 550, phy band, termohigrometer, botol sampel air, tali ukur, cangkul, ring tanah (diameter $5 \mathrm{~cm}$ ), palu karet, pisau tanah, spidol permanen, soil PH dan moisture tester, dan kamera. Bahan yang digunakan adalah kantong plasik (untuk me-nyimpan sampel tanah), plakband, peta lokasi penelitian dan titik penga-matan.

Dalam penelitian ini, komponen dan parameter yang diamati adalah sebagai berikut:

Tabel 1. Parameter iklim dalam rangka penelitian

\begin{tabular}{|c|c|c|c|c|c|}
\hline No & $\begin{array}{c}\text { Parameter } \\
\text { Lingkungan }\end{array}$ & Satuan & $\begin{array}{c}\text { Metode } \\
\text { Pengumpulan }\end{array}$ & $\begin{array}{l}\text { Metode } \\
\text { Analisis }\end{array}$ & $\begin{array}{l}\text { Alat Yang } \\
\text { Digunakan }\end{array}$ \\
\hline 1. & Tipe Iklim & - & Studi Pustaka & Schmidt-Ferguson & - \\
\hline 2. & Curah Hujan & $\mathrm{Mm}$ & Studi Pustaka & Tabulasi & - \\
\hline 3. & Hari Hujan & Hari & Studi Pustaka & Tabulasi & - \\
\hline 4. & $\begin{array}{l}\text { Suhu Udara } \\
\text { (wilayah dan mikro) }\end{array}$ & ${ }^{\circ} \mathrm{C}$ & $\begin{array}{l}\text { Studi Pustaka } \\
\text { dan }\end{array}$ & Tabulasi & Termometer \\
\hline 5. & $\begin{array}{l}\text { Kelembaban } \\
\text { (wilayah dan mikro) }\end{array}$ & $\%$ & $\begin{array}{l}\text { Studi Pustaka } \\
\text { dan }\end{array}$ & Tabulasi & Higrometer \\
\hline 6. & Kondisi angin & $-/$ knot & Studi Pustaka & Tabulasi & - \\
\hline 7. & Radiasi matahari & $\%$ & Studi Pustaka & Tabulasi & - \\
\hline
\end{tabular}

Perikanan UNIPA, Kecerahan dengan alat secci disk, Total Padatan
1. Iklim, parameter iklim yang dikaji adalah 7 (tujuh) parameter, yang terdiri atas data primer dan data sekunder, seperti terlihat pada Tabel 1.

Data primer iklim (mikro) yang diukur secara langsung adalah suhu dan kelembaban udara, yang diukur pada ketinggian 1,2 $\mathrm{m}$ dari permukaan tanah pada jam yang sama untuk tiap pengukuran, yaitu pada jam 07.00, jam 12.00 dan jam 15.00. Data sekunder iklim yang dikumpulkan berupa temperatur maksimum dan minimun, kelembaban, jumlah hari hujan, curah hujan, lama penyinaran matahari, arah angin dan kecepatan angin. Data ini dikumpulkan secara periodik, untuk 10 tahun.

2. Erosi (erosi dinding kanal), Pendugaan erosi dengan parameter jenis tanah, jenis tutupan lahan pada rona awal, curah hujan, panjang lereng, kemiringan lereng, dan teknik pengelolaan tanah.

3. Perhitungan kualitas air (sifat fisik), dengan parameter Bau dan Rasa secara Organoleptik, Warna secara visual, Kekeruhan dengan alat Turbidimeter di Laboratorium

Terlarut (TDS) dan Total Padatan

Tersuspensi (TSS) melalui analisis 
secara gravimetri di Laboratorium Badan Lingkungan Hidup Kabupaten Manokwari, Suhu Air dengan alat temometer air, sumber data merupakan data primer.

4. Perhitungan jumlah dan dimensi fisik kanal. Parameter yang digunakan yaitu jumlah dan sebaran kanal serta dimensi ukuran fisik kanal (meliputi panjang, lebar, dalam dan jarak antar kanal)

5. Prediksi jumlah emisi karbondioksida $\left(\mathrm{CO}_{2}\right)$ yang dihasilkan akibat pembukaan kanal. Parameter yang digunakan adalah luas hutan dan atau penutupan hutannya (ha) yang berubah fungsi yang sumber datanya melalui perhitungan luas areal yang berubah fungsi dan data koefisien yang mengkuantifikasi emisi atau penyerapan per unit aktivitas, merupakan perubahan stock karbon (pengeluaran emisi dan atau penyerapan) per unit areal yang diakibatkan oleh aktivitas pengelolaan tertentu (ton/ha).

6. Jumlah tumbuhan (struktur/ potensi tegakan dan kemantapan tegakan) Parameter yang akan diteliti meliputi jenis pohon, jumlah pohon per hektar, dan produktivitas per hektar (tinggi dan diameter batang), sumber data merupakan data primer dan sekunder.

7. Pendugaan cadangan karbon dalam tanah (dibawah permukaan), Parameter yang akan diteliti luas, kedalaman tanah, bobot isi (Bulk Density/BD) dan kandungan karbon $\left(\mathrm{C}_{\text {organik }}\right)$.

Penelitian menggunakan metode survei dan pengumpulan data-data dan informasi yang dibutuhkan. Analisis data sesuai dengan kebutuhan yaitu perubahan biofisik-kimia lahan yang ditimbulkan dan jumlah emisi karbondioksida yang dihasilkan oleh pembukaan kanal. Untuk melihat komposisi dan struktur tegakan dilakukan analisis vegetasi

Data primer iklim (mikro) yang diukur secara langsung adalah suhu dan kelembaban udara, yang diukur pada ketinggian 1,2 $\mathrm{m}$ dari permukaan tanah pada jam yang sama untuk tiap pengukuran, yaitu pada jam 07.00, jam 12.00 dan jam 15.00. Data sekunder iklim yang dikumpulkan berupa temperatur mak-simum dan minimun, kelembaban, jumlah hari hujan, curah hujan, lama penyinaran matahari, arah angin dan kecepatan angin. Data ini dikumpulkan secara periodik, untuk 10 tahun

8. Erosi (erosi dinding kanal), Pendugaan erosi dengan parameter jenis tanah, jenis tutupan lahan pada rona awal, curah hujan, panjang lereng, kemiringan lereng, dan teknik pengelolaan tanah.

9. Perhitungan kualitas air (sifat fisik), dengan parameter Bau dan Rasa secara Organoleptik, Warna secara visual, Kekeruhan dengan alat Turbidimeter di Laboratorium Perikanan UNIPA, Kecerahan dengan alat secci disk, Total Padatan Terlarut (TDS) dan Total Padatan Tersuspensi (TSS) melalui analisis secara gravimetri di Laboratorium Badan Lingkungan Hidup Kabupaten Manokwari, Suhu Air dengan alat temometer air, sumber data merupakan data primer.

10. Perhitungan jumlah dan dimensi fisik kanal. Parameter yang digunakan yaitu jumlah dan sebaran kanal serta dimensi ukuran fisik kanal (meliputi panjang, lebar, dalam dan jarak antar kanal)

11. Prediksi jumlah emisi karbondioksida $\left(\mathrm{CO}_{2}\right)$ yang dihasil-kan akibat pembukaan kanal. Para- 
meter yang digunakan adalah luas hutan dan atau penutupan hutannya (ha) yang berubah fungsi yang sumber datanya melalui perhitungan luas areal yang berubah fungsi dan data koefisien yang mengkuantifikasi emisi atau penyerapan per unit aktivitas, merupakan perubahan stock karbon (pengeluaran emisi dan atau penyerapan) per unit areal yang diakibatkan oleh aktivitas pengelolaan tertentu (ton/ ha).

12. Jumlah tumbuhan (struktur/ potensi tegakan dan kemantapan tegakan) Parameter yang akan diteliti meliputi jenis pohon, jumlah pohon per hektar, dan produktivitas per hektar (tinggi dan diameter batang), sumber data merupakan data primer dan sekunder.

13. Pendugaan cadangan karbon dalam tanah (dibawah permukaan), Parameter yang akan diteliti luas, kedalaman tanah, bobot isi (Bulk Density/BD) dan kandungan karbon $\left(\mathrm{C}_{\text {organik }}\right)$.

\section{Metode}

Penelitian menggunakan metode survei dan pengumpulan data-data dan informasi yang dibutuhkan. Analisis data sesuai dengan kebutuhan yaitu perubahan biofisik-kimia lahan yang ditimbulkan dan jumlah emisi karbon dioksida yang dihasilkan oleh pembukaan kanal. Untuk melihat komposisi dan struktur tegakan dilakukan analisis vegetasi

\section{A. Pengumpulan Data}

Pengumpulan data primer dilakukan pada titik sampling yang telah ditentukan secara purposif atau sengaja pada jalur kanal guna me-ngkaji perubahan biofisik-kimia lahan yang ditimbulkan dan pada areal konsesi yang diperkirakan akan berdampak langsung akibat pembukaan kanal, dan melakukan pengambilan data komposisi dan struktur tegakan serta pendugaan karbon di dalam tanah (di bawah permukaan). Data sekunder didapatkan dari berbagai instansi terkait dan studi pustaka yang terdiri dari :

1. Peta Areal Kerja IUPHHBK PT. ANJ Agri Papua,

2. Dokumen ANDAL IUPHHBK PT. ANJ Agri Papua

3. Faktor Emisi dari tiap Penutupan Lahan

4. Data Iklim dari BMG Sorong

\section{B. Analisis Data}

Analisis data yang dilakukan meliputi perhitungan analisis vegetasi pada struktur dan komposisi tegakan, kajian perubahan biofisik-kimia lahan dan dugaan jumlah emisi karbon dioksida akibat pembukaan kanal.serta perhitungan cadangan dalam tanah.

a. Perhitungan struktur/potensi tegakan dan kemantapan tegakan

Penentuan jumlah pohon/ tanaman yang hilang sebagai se-bagai akibat pembukaan kanal, datanya didapatkan dari sekunder yaitu data rona awal lingkungan dan data perhitungan jumlah tana-man sagu yang ditebang dari per-usahaan dan data primer mela-lui perhitungan analisis vegetasi.

Metode yang digunakan dalam pengamatan vegetasi adalah metode garis (jalur) berpetak, yaitu metode yang dianggap sebagai modifikasi metode petak ganda atau metode jalur, yakni dengan cara melompati satu atau lebih petak-petak dalam jalur sehingga sepanjang garis rintis terdapat petakpetak pada jarak tanam ter-tentu yang sama (Kusmana. 1997). Gambar 3. memperlihatkan pelak-sanaan metode garis berpetak di lapangan. Dari data yang dikum-pulkan, digunakan untuk 
meng-hitung frekuensi, kerapatan, domi-nasi jenis dan nilai penting jenis

Petak pengamatan untuk semai berukuran $(2 \times 2) \mathrm{m}$, pancang $(5 \times 5) \mathrm{m}$, tiang $(10 \times 10) \mathrm{m}$ dan pohon $(20 \times 20) \mathrm{m}$. Untuk tingkat pohon dan tiang dilakukan peng-ukuran dan pencatatan nama jenis, diameter dan tinggi pohon, se-dangkan untuk pancang dan semai dilakukan pencacatan nama pohon dan jenisnya.

Kriteria yang digunakan untuk tanaman non sagu adalah :

Semai : Dari anakan sampai vegetasi yang tingginya $<1,5 \mathrm{~m}$,

Pancang : Tinggi dari 1,5 $\mathrm{m}$ dengan diameter batang sampai 9 $\mathrm{cm}$

Tiang : Diameter batang dari 10 cm sampai dengan $19 \mathrm{~cm}$

Pohon : Diameter batang $\geq 20$

Kriteria yang digunakan untuk tanaman sagu adalah :
Semai : Semaian adalah tana- man muda yang batang- nya bebas daun hingga ketinggian 0 - $0,50 \mathrm{~m}$

Pancang : Tanaman yang batangnya bebas daun antara 0,50-1,50 m

Tiang : Tanaman yang batangnya bebas daun dari ketinggian $1,50-5 \mathrm{~m}$

Pohon : Tanaman yang batangnya bebas daun pada ketinggian $5 \mathrm{~m}$ atau lebih

Perhitungan besarnya nilai kuantitatif parameter vegetasi dihitung dengan persaman matematis yang dikembangkan oleh Kusmana (1997) sebagai berikut :

a. Kerapatan

$$
\begin{aligned}
\text { Kerapatan }(K) & =\frac{\text { Jumlah Individu }}{\text { Luas Petak Contoh }} \\
\text { K Relatif }(K R) & =\frac{\text { K Suatu Jenis }}{\text { K Total Seluruh Jenis }} \times 100 \%
\end{aligned}
$$

\section{b. Frekuensi}

$$
\begin{gathered}
\text { Frekuensi }(\mathrm{F})=\frac{\text { Jumlah Sub petak ditemukan suatu spesies }}{\text { Jumlah seluruh sub Petak Contoh }} \\
\text { F Relatif }(\mathrm{FR})=\frac{\text { F suatu spesis }}{\text { F seluruh spesies }} \times 100 \%
\end{gathered}
$$

\section{c. Dominansi}

$$
\begin{gathered}
\text { Dominansi }(\mathrm{D})=\frac{\text { Luas Bidang Dasar suatu spesies }}{\text { Luas Petak Contoh }} \\
\text { D Relatif (DR) }=\frac{\text { D suatu spesis }}{\text { D seluruh spesies }} \times 100 \%
\end{gathered}
$$

Luas Bidang Dasar (LBD) atau Basal Area (BA) merupakan suatu luasan areal dekat permukaan tanah yang dikuasai oleh tumbuhan. Untuk pohon, basal area diduga dengan me-ngukur diameter batang. Dengan asumsi bahwa penampang melintang batang suatu pohon berbentuk lingkaran, basal area pohon tersebut dihitung dengan persamaan matematis yang dikembangkan oleh Kusmana (1997) sebagai berikut :

$$
\begin{aligned}
\mathrm{BA} & =\pi \cdot \mathrm{R}^{2} \\
& =1 / 4 \cdot \pi \cdot \mathrm{D}^{2} \\
& =1 / 4 \pi(\mathrm{d} / 100)^{2}
\end{aligned}
$$

Dimana :
BA : Basal Area atau Luas Bidang Dasar (LBD)

$\mathrm{R}$ : Jari-jari lingkaran dan penampang lintang batang

D : Diameter batang pohon

\section{d. Indeks Nilai Penting (INP)}

INP dihitung dengan menjumlahkan nilai Frekuensi Relatif (FR), Kerapatan Relatif (KR) dan Dominansi Relatif (DR). tetapi untuk vegetasi yang besaran parameternya tidak dapat diukur (pengukuran pada tingkat semai), maka INP bisa diperoleh dengan menjumlahkan KR dan FR saja (Kusmana, 1997).

$$
\mathrm{INP}=\mathrm{KR}+\mathrm{FR}+\mathrm{DR}
$$

Dimana : 


$$
\begin{array}{ll}
\text { INP } & \text { : Indeks Nilai Penting } \\
\text { KR } & : \text { Kerapatan Relatif } \\
\text { FR } & : \text { Frekuensi Relatif } \\
\text { DR } & : \text { Dominansi Relatif }
\end{array}
$$

\section{e. Volume Kayu}

Selain kerapatan, frekuensi dan kelindungan (termasuk diameter), parameter kuantitatif lainnya yang bisa diukur yaitu tinggi pohon. Anonim (1976) menjelaskan persamaan mate-matis untuk mencari volume kayu dengan angka bentuk 0.7 digunakan sebagai berikut:

$$
\mathrm{V}=0,25 \times \mathrm{D}^{2} \times \pi \times \mathrm{T} \times 0.7
$$

Keterangan:

$$
\begin{aligned}
\mathrm{V}= & \text { Volume batang bebas ca- } \\
& \text { bang dan banir (m) } \\
\mathrm{D}= & \text { Diameter batang setinggi } \\
& \text { dada }(\mathrm{m}) \\
\mathrm{T}= & \text { Tinggi batang bebas cabang } \\
& \text { dan banir }(\mathrm{m}) \\
\pi= & \frac{22}{7} \text { atau } 3.14 \\
0.7= & \text { Angka bentuk }
\end{aligned}
$$

\section{f. Perubahan BioFisik-Kimia Lahan}

\section{Iklim}

Komponen iklim yang dihimpun selanjutnya diseleks dan dikelompokkan secara statistik dan disajikan dalam bentuk tabulasi, sehingga memudahkan dalam menentukan pola iklim regional daerah penelitian. Data tersebut dikalkulasikan dalam rata-rata, maksimum dan minimum.

\section{Erosi Tanah (erosi dinding kanal)}

Prediksi laju erosi tanah (erosi dinding kanal) pada lokasi penelitian akan dilakukan menggunakan metode USLE (Universal Soil Loss Equation) yang dikembangkan oleh Wischmeier dan Smith (1978) dalam Asdak, (2004) dengan persamaan sebagai berikut :

$$
\mathrm{A}=\mathrm{R} \times \mathrm{K} \times \mathrm{LS} \times \mathrm{C} \times \mathrm{P}
$$

dimana :

$$
\begin{aligned}
\mathrm{A}= & \begin{array}{l}
\text { Laju erosi tanah maksimum } \\
\text { (ton/ha/tahun) }
\end{array} \\
\mathrm{R}= & \text { Faktor erosivitas hujan } \\
\mathrm{K}= & \text { Faktor erodibilitas tanah } \\
\mathrm{LS}= & \text { Indeks faktor panjang dan } \\
& \text { kemiringan lereng } \\
\mathrm{C}= & \text { Indeks faktor pengelolaan } \\
& \text { tanaman } \\
\mathrm{P}= & \text { Indeks faktor teknik kon- } \\
& \text { servasi tanah }
\end{aligned}
$$

Perhitungan kualitas air (sifat fisik),

Analisis data kualitas air (sifat fisik) kanal dilakukan dengan cara membandingkan data hasil pengukuran/ analisa laboratorium terhadap baku mutu kualitas air sungai menurut Peraturan Pemerintah Nomor 82 tahun 2001 tentang Persyaratan Kualitas Air dan SNI. 6989.57.2008 (metoda pengambilan contoh air permukaan).

g. Prediksi jumlah emisi karbon di atas permukaan akibat pembukaan kanal

Prediksi jumlah emisi karbon akibat pembukaan kanal, melalui perhitungan luas hutan dan atau penutupan hutannya (ha) yang berubah fungsi dan data koefisien yang mengkuanti-fikasi emisi atau penyerapan per unit aktivitas, merupakan peru-bahan stock karbon (pengeluaran emisi dan atau penyerapan) per unit areal yang diakibatkan oleh aktivitas pengelolaan tertentu (ton/ha). Untuk memprediksi jumlah emisi karbon dioksida adalah dengan persamaan mate-matis yang dikembangkan oleh IPCC (2006), sebagai berikut :

$$
\mathrm{EE}=\mathrm{AD} \times \mathrm{EF}
$$

Dimana, untuk sektor berbasis lahan ; $\mathrm{EE}$ : Emision Estimate (Ton $\left.\mathrm{CO}_{2}\right)$ 
AD : Activity Data, luas areal yang kena dampak dari kegiatan pengelolaan tertentu Secara sederhana activity data merupakan perubahan luas hutan dan atau penutupan hutannya (ha).

EF : Emission Factor, Koefisien yang mengkuantifikasi emisi atau penyerapan per unit aktivitas, merupakan perubahan stock karbon (pengeluaran emisi dan atau penye-rapan) per unit areal yang diakibatkan oleh aktivitas pengelolaan tertentu (ton/ha).

h. Perhitungan cadangan karbon (carbon stock) dalam tanah (dibawah permukaan)

Tanah merupakan salah satu dari tiga penyimpanan karbon (carbon pool) di darat selain biomasa tanaman (tanaman hidup) dan tanaman yang mati (nekromasa) (IPCC, 2006). Pendugaan cadangan karbon di dalam tanah dibagi dua yaitu :

\section{Tanah Mineral}

Parameter yang digunakan untuk perhitungan pendugaan cadangan karbon dibawah tanah yaitu bobot isi (Bulk Density/BD) dan kandungan karbon (Corganik), persamaan yang digunakan adalah

$$
\mathrm{KC}=\mathrm{BD} \times \mathrm{A} \times \mathrm{C}
$$

Dimana :

$\mathrm{KC}$ : Kandungan Karbon dalam ton

BD : Bobot isi (BD) tanah gambut dalam $\mathrm{g} / \mathrm{cm}$ atau ton $/ \mathrm{m}^{3}$

A : Luas Tanah dalam $\mathrm{m}^{2}$

C : Kadar karbon (Corganik), dalam persen

\section{Tanah Gambut}

Parameter yang digunakan untuk perhitungan pendugaan cadangan kar- bon dibawah permukaan adalah luas lahan gambut, kedalaman tanah gambut, bobot isi (Bulk Density/BD) dan kandungan karbon $\left(\mathrm{C}_{\text {organik }}\right)$ pada setiap jenis tanah gambut, persamaan yang digunakan adalah

$$
\mathrm{KC}=\mathrm{BD} \times \mathrm{A} \times \mathrm{D} \times \mathrm{C}
$$

Dimana :

$\mathrm{KC}$ : Kandungan Karbon dalam ton

BD : Bobot isi (BD) tanah gambut dalam $\mathrm{g} / \mathrm{cm}$ atau ton $/ \mathrm{m} 3$

A : Luas Tanah Gambut dalam m2

D : Kedalaman Gambut dalam m

C : Kadar karbon (Corganik), dalam persen

\section{HASIL DAN PEMBAHASAN}

\section{Struktur/Potensi Tegakan dan Ke- mantapan Tegakan}

a. Penutupan Lahan Areal Kon-sesi PT. ANJ Agri Papua

Areal konsesi PT. ANJ Agri Papua digolongkan dalam kelas penutupan lahan yaitu Hutan Mangrove, Hutan Campuran, Belukar, Hutan Sagu dan Hutan Sagu Campuran. Berdasarkan luas kelas penutupan lahan, areal konsesi PT.ANJ Agri Papua didominasi oleh Hutan Sagu (73.29\%), disusul oleh Hutan Campuran $(11.20 \%)$ dan Hutan Sagu Campuran (10.22 \%). Sisanya masing- masing oleh kelas penutupan Belukar dan kelas penutupan Hutan Mangrove. Secara detail luas masingmasing penutupan lahan dan fungsi hutan seperti disajikan pada Tabel 2 .

Pada Tabel 2, tampak bahwa areal konsesi PT. ANJ Agri Papua berdasarkan fungsi hutan sebagian besar tergolong hutan produksi $(33.155 \mathrm{Ha})$ dan Hutan Produksi Tetap (6.845 Ha).

Tipe hutan di areal IUPHHBKHA Sagu PT. ANJ Agri Papua termasuk tipe hutan hujan rawa primer yang 
didominasi oleh Pohon Sagu (Metroxylon Spp.) yang terdiri dari hutan Rawa Sagu, Hutan Sagu dan Hutan Sagu Campuran. Jenis-jenis lain yang juga tumbuh di areal IUPHHBK adalah jenis Instia sp., Dryobalanops sp., Avicenia Spp., Rhizophora Spp., Sonneratia Spp., Nypah fruticans, dll.

\section{b. Potensi Sagu}

Potensi hutan sagu tergolong tinggi dengan rata-rata per hektar untuk semua jenis sagu berdiameter rata-rata $40 \mathrm{~cm}$ adalah 241,24 pohon/ha dan pohon masak panen rata 44,22 pohon/ ha, dengan jumlah rumpun sebanyak 217,24 rumpun/ha. Berat Jenis log sagu sebesar 0,9 , sehingga setiap log sagu dengan diameter $40 \mathrm{~cm}$ dan panjang 13 meter mempunyai berat 1,4 ton. Dari pohon sagu masak panen berdasarkan penelitian perusahaan terdapat rendemen sagu $12,5 \%$, sehingga untuk setiap pohon sagu masak panen terdapat ratarata 1,4 ton pati sagu dihasilkan 0,175 ton $=175 \mathrm{~kg}$.

Tabel 2. Luas areal IUPHHBK-HA Sagu PT. ANJ Agri Papua menurut fungsi dan penutupan lahan

\begin{tabular}{clcccc}
\multirow{2}{*}{ No } & \multirow{2}{*}{ Penutupan } & \multicolumn{2}{c}{ Fungsi Hutan } & \multicolumn{2}{c}{ Jumlah } \\
\cline { 3 - 6 } & & HPT & HP & Ha & $\%$ \\
\hline 1 & Hutan Mangrove & 0 & 53 & 53 & 0,13 \\
2 & Hutan Campuran & 1.017 & 3.462 & 4.479 & 11,20 \\
3 & Belukar & 91 & 556 & 647 & 1,62 \\
4 & Hutan Sagu & 4.105 & 25.210 & 29.315 & 73,29 \\
5 & Hutan Sagu Campuran & 1.282 & 2.805 & 4.087 & 10,22 \\
6 & Tertutup Awan & 350 & 1.069 & 1.419 & 3,55 \\
\hline & Jumlah & 6.845 & 33.155 & 40.000 & 100 \\
\hline
\end{tabular}

Sumber : Hasil Pengukuran secara digital planimetris peta penafsiran potret udara yang dikoreksi dengan Citra Landsat ETM-5 542, tahun 2007

Berdasarkan hasil analisis vegetasi pada hutan sagu petak pengamatan dengan luasan 1 ha disekitar kanal primer didapatkan kerapatan jenis pohon sagu adalah 134 pohon/ha dengan nilai frekuensi sebesar 1 yang berarti pohon sagu menyebar merata disemua petak contoh yang diamati dengan nilai dominansi sebesar $17.76 \mathrm{~m} 2 / \mathrm{ha}$. Dari hasil analisis vegetasi ini menunjukan bahwa areal konsesi PT. ANJ Agri Papua memiliki potensi sagu yang tinggi dan menyebar merata pada semua areal konsesi dengan ditunjukan dengan nilai Indeks Nilai Penting mencapai 300\%.

Pohon sagu berdiameter ratarata $40 \mathrm{~cm}$ yang hilang akibat pembukaan kanal seluas 82.35 ha adalah sebanyak 19.866 pohon dan yang telah masak tebang sebanyak 3.642 pohon, sehingga pati sagu yang hilang akibat pembukaan kanal seluas 82.35 ha sebanyak 637.27 ton atau $637,265.48$ $\mathrm{kg}$. Data potensi dan produksi pati sagu areal konsesi PT. ANJ Agri Papua disajikan padaTabel 3 .

\section{Perubahan BioFisik - Kimia Lahan Akibat Pembangunan Kanal}

a. Iklim

Berdasarkan data iklim periode 1999-2010 dari BMG DEO Sorong yang dituangkan dalam dokumen ANDAL IUPHHBK PT. ANJ, curah hujan di 
lokasi penelitian tergolong cukup tinggi, yaitu mencapai $2.879 \mathrm{~mm} / \mathrm{tahun}$, dengan jumlah hari hujan rata-rata 196 hari/tahun. Curah hujan maksimum jatuh pada bulan Juni (377 mm/bulan), sedangkan curah hujan minimum terjadi pada bula Februari (158 mm/bulan). Bulan basah yaitu curah hujan $>100 \mathrm{~mm} /$ bulan (Schmidt dan Ferguson, 1951) terjadi sepanjang tahun dan tidak dijumpai bulan kering ( $<60 \mathrm{~mm} / \mathrm{bulan})$.

Dengan demikian menurut klasifikasi iklim Schmidt dan Ferguson, tipe iklim di kawasan ini tergolong tipe iklim A, yakni daerah sangat basah (very wet), dengan perbandingan bulan kering dan bulan basah $(\mathrm{Q})=0 \%$, sedangkan menurut klasifikasi Oldeman iklim di wilayah areal kerja IUPHHK-Sagu ini tergolong tipe A yang memberikan gambaran bahwa bulan basah (curah hujan $>200 \mathrm{~mm} /$ bulan) terjadi selama $\geq 8$ bulan berturut-turut dan tanpa bulan kering (curah hujan $<100 \mathrm{~mm} /$ bulan).

Data iklim dari tahun 2011 2013 hasil pengukuran PT. ANJ Agri Papua di base camp menunjukan bahwa curah hujan pada tahun 2011 mencapai $1.888,26 \mathrm{~mm} /$ tahun dan pada tahun 2012 mencapai $2.119,4 \mathrm{~mm} /$ tahun dengan curah hujan maksimum pada bulan Maret 2012 (391.2 mm/bulan), sedangkan curah huja minimum terjadi pada bulan Agustus 2011 (50.3 mm/ bulan).

Bulan basah dalam tahun 2012 sebanyak 11 bulan dan bulan kering sebanyak 1 bulan yaitu pada bulan September. Sedangkan pada tahun 2011 bulan basah sebanyak tujuh bulan yaitu bulan Maret, April, Mei Juni, Juli, September dan Desember sedangkan bulan kering sebanyak 5 bulan yaitu pada bulan Januari, Februari, Agustus, September dan Oktober.

Tabel 3. Potensi tegakan sagu dan produksi pati di Areal PT. ANJ Agri Papua

\begin{tabular}{|c|c|c|c|}
\hline \multicolumn{2}{|c|}{ Tegakan Sagu (1 Ha) } & \multicolumn{2}{|c|}{ Tegakan $(82.35 \mathrm{Ha})$} \\
\hline Pohon sagu & 241 pohon/ha & 19.866 & pohon \\
\hline Pohon masak tebang & 44 pohon/ha & 3.642 & pohon \\
\hline Jumlah rumpun & 217 rumpun/ha & 17889.71 & rumpun \\
\hline \multicolumn{2}{|c|}{ Pati Sagu Untuk (1 Ha) } & \multicolumn{2}{|c|}{ Pati Sagu $(82.35 \mathrm{Ha})$} \\
\hline Berat Pati sagu & 61.908 ton/ha & 5098.12 & ton \\
\hline rendemen pohon masak tebang & $12.5 \%$ & 12.5 & $\%$ \\
\hline berat bersih pati sagu (ton) & 7.74 ton & 637.27 & ton \\
\hline berat bersih pati sagu $(\mathrm{Kg})$ & $7,738.50 \mathrm{Kg}$ & $637,265.48$ & $\mathrm{Kg}$ \\
\hline
\end{tabular}

Secara global telah terjadi perubahan pola dan jumlah curah hujan sebagai akibat dari efek gas rumah kaca yang menyebabkan peningkatan suhu permukaaan bumi dan pada penguapan dari badan-badan air.

Suhu udara rata-rata daerah penelitian berkisar antara $26-33^{\circ} \mathrm{C}$, minimum berkisar antara $26-28{ }^{\circ} \mathrm{C}$, dan maksimum: $29-33{ }^{\circ} \mathrm{C}$. Kelembapan udara relatif berkisar antara $75-84 \%$. Kelembaban udara terendah terjadi pada bulan September dan Oktober (75\%), sedangkan kelembapan udara tertinggi dijumpai pada bulan Februari (84\%).

Intensitas penyinaran matahari pada areal IUPBK PT. ANJ Agri Papua umumnya tergolong tinggi. Hanya pada bulan Desember dan Januari yang intensitas penyinaran mataharinya kurang dari $50 \%$, sedangkan bulan lainnya umumnya di atas $50 \%$. Radiasi terendah terjadi pada bulan Desember $(45,8 \%)$, sedang radiasi tertinggi terjadi pada bulan Agustus (92,1\%). 
Rata-rata kecepatan angin di areal kerja berkisar 4,8-7,8 $\mathrm{m} /$ detik, yang tergolong pada derajat kecepatan 3 dan 4 menurut skala Beaufort. Kecepatan angin dengan derajat kecepatan 3 (3,4-5,4 m/detik), dicirikan daun-daun dan ranting kecil bergerak terus dan bendera berkibar. Di kawasan studi kecepatan angin dengan derajat kecepatan 3 ini dijumpai pada bulan AprilJuni dan Desember (4,8-5,0 m/detik). Kecepatan angin dengan derajat kecepatan 4 (5,5-7,9 m/detik), dicirikan oleh debu pasir terangkat dan kertas-kertas terbawa, serta ranting-ranting bergerak. Di kawasan studi kecepatan angin dengan derajat kecepatan 4 ini dijumpai pada bulan Juli-Nopember dan JanuariMaret (5,5-7,8 m/detik).

Kecepatan angin tertinggi dijumpai pada bulan September $(7,8$ $\mathrm{m}$ /detik). Arah angin dominan adalah ke arah tenggara dan timur. Pada bulan Mei-Oktober umumnya angin berhembus ke tenggara.

Perubahan iklim yang terjadi yaitu pada perubahan iklim mikro yang dapat dilihat dengan adanya perubahan suhu dan kelembapan yang nampak terjadi di basecamp, pabrik dan kanal primer, dimana terjadi peningkatan hal ini disebabkan karena terjadinya pembukaan lahan untuk kegiatan konstruksi.

\section{b. Erosi Tanah (erosi dinding kanal)}

Secara umum daerah penelitian mempunyai bentuk lahan teras (terraces), rawa gambut (peat swamps) dan rawa pasang surut (tidal swamps). Bentuk lahan teras terdapat di sebelah utara yang merupakan perbukitan. Bentuk lahan teras ini mempunyai hubungan pengaruh dengan bentuk lahan rawa gambut dan rawa pasang surut yang berada di sebelah selatan. Pada lahan rawa gambut dan rawa pasang surut adalah suatu wilayah endapan yang merupakan hasil erosi dari daerah perbukitan tersebut.

Dalam dokumen ANDAL menunjukkan bahwa laju erosi pada daerah IUPHHBK PT ANJ tergolong sangat rendah dan mempunyai nilai tingkat bahaya erosi sangat kecil dengan nilai A (Laju erosi tanah maksimum) pada wilayah Satuan Peta Tanah (SPT) 1 sebesar 4,03 ton/ha/thn dan SPT 2 sebesar 0,07 ton/ha/thn. Hal ini karena wilayah ini secara posisi bukan wilayah erosi tetapi justru wilayah pengendapan

Perubahan kondisi biofisik dalam pembuatan kanal adalah terendapnya masa gambut dan terjadinya erosi pada dinding kanal. Erosi terjadi sebagai akibat dari aliran air dalam kanal yang berakibat pada pengikisan dinding kanal dan kemudian berlanjut dengan longsornya tepi kanal (channel banks). Hal tersebut dapat dilihat dengan terjadinya pendangkalan kanal akibat deposit sedimen, peningkatan TSS dan kecerahan air.

Erosi pada dinding kanal akan dipercepat jika kecepatan aliran air drainase melebihi $1,50 \mathrm{~m} / \mathrm{s}$. Nilai ini sedikit bervariasi tergantung dari sifat gambut. Gambut dengan bahan fibrik berbeda dengan bahan yang lebih saprik. Selain kecepatan air drainase disebabkan juga oleh pembuatan tepi kanal (channel banks) yang tidak ber-bentuk "V" melainkan berbentuk "U" sehingga membuat longsoran pada tepi/dinding kanal hal ini akan diperparah oleh kikisan log sagu yang ditarik dengan tucboat pada tahap operasional.

\section{c. Perhitungan Kualitas Air}

Kegiatanpada tahap pembangunan kanal berdampak terhadap penurunan kualitas air sungai maupun rawa. Kegiatan-kegiatan yang diprakirakan akan mempengaruhi penurunan kualitas air sungai pada tahap ini adalah mobi- 
lisasi peralatan dan bahan dan pembangunan log pond.

Penelitian kualitas air mencakup pengukuran langsung di lapangan dan analisis laboratorium. Parameter kualitas air tanah disesuaikan dengan Peraturan Pemerintah No. 82 tahun 2001 tentang persyaratan kualitas air. Hasil pengamatan dan analisis kualitas air kanal disajikan pada Lampiran 4.

Berdasarkan hasil pengamatan dan analisis kualitas air kanal menunjukkan bahwa keadaan fisik dari air kanal masih sesuai dengan baku mutu, kecuali TSS, kekeruhan dan PH. Sedangkan untuk air kanal berwarna merah kecoklatan hingga coklat kehitaman.

Bau dan Rasa. Sampel air kanal dari keempat titik pengamatan tercium tidak berbau dan tidak beras.

Warna. Sampel air kanal dari keempat titik pengamatan berwarna merah kecoklatan hingga coklat kehitaman. Sampel air pada daerah yang tidak terusik berwarna merah kecoklatam hal ini disebabkan karena berada pada daerah gambut sehingga banyak-nya zat-zat organik yang telah mem-busuk, tanin, asam humus, dan lain-lain. Sedangkan warna pada daerah kanal berwarna kecoklatan hingga coklat kehitaman dikarenakan terjadinya erosi dan sendimentasi pada kanal.

Kekeruhan. Nilai kekeruhan suatu parameter yang berkaitan dengan kualitas air. Hasil pengamatan untuk air kanal pada daerah yang tidak terusik menunjukan nilai kekeruhan sebesar 0 NTU menunjukkan nilai yang belum melebihi batas ambang yang ditentukan yaitu 5 NTU (nephelometric turbidity units). Sedangkan pada kanal menunjukkan adanya kekeruhan dengan nilai melewati batas ambang yang mencapai 52 -106 NTU yang disebabkan oleh erosi atau abrasi dan aktifitas kontruksi pembangunan kanal.
Kecerahan. Kecerahan merupakan faktor ekologik penting dalam kehidupan air. Hal ini karena kecerahan menunjukkan intensitas cahaya tertentu yang dapat menembus kedalaman air. Hasil pengamatan untuk air kanal pada daerah yang tidak terusik menunjukan kecerahan yang baik sedangkan kecerahan air dari seluruh lokasi menunjukkan kisaran $24-26 \mathrm{~cm}$. Kecerahan paling rendah terdapat pada boundary kanal sekunder dan kanal primer sedangkan pada kecerahan semakin tinggi.

Total Padatan Terlarut (TDS). TDS bukan merupakan polutan utama, namun lebih sebagai karakteristik nilai estetika untuk air minum. Hasil pengukuran pada daerah tidak terusik menunjukan nilai TDS sebesar $110-124$ $\mathrm{mg} / \mathrm{L}$ sedangkan pada daerah kanal nilai TDS sebesar 124 -194 mg/L dimana TDS tertinggi pada boundary kanal. Nilai TDS dalam air yang berasal dari keempat lokasi air pengamatan belum melebihi ambang batas yang ditentukan yaitu $1000 \mathrm{mg} / \mathrm{l}$.

Total Padatan Tersuspensi (TSS). TSS berpengaruh terhadap proses sedimentasi sepanjang aliran kanal. Hasil pengukuran menunjukkan bahwa nilai TSS pada daerah tidak terusik sebesar 22 - $48 \mathrm{mg} / \mathrm{L}$ hal ini menunjukan nilai TSS belum melewati ambang yang ditentukan yaitu $50 \mathrm{mg} / \mathrm{l}$. Ha. Sedangkan pada daerah kanal nilai TSS telah melewati ambang batas yaitu berkisar antara 44 - 106 mg/L. Peningkatan TSS disebabkan karena kegiatan mobilisasi peralatan dan bahan pembangunan kanal dan pembangunan log pond.

Suhu Air. Suhu air diupayakan sedemikian rupa sehingga diharapkan tidak meningkat dibandingkan suhu aslinya. Pengukuran suhu in situ dilaksanakan pada saat pengambilan sampel, dan kondisi awal telah dicatat. Semua data suhu merupakan hasil pengukuran 
suhu ambien dengan ketelitian $0,1^{\circ} \mathrm{C}$. Tidak terdapat buangan efluen dengan temperatur tinggi (thermal effluent) yang mempengaruhi suhu air, maka tidak perlu dilakukan perhitungan $\mathrm{T}$ (perubahan suhu). Kriteria ini akan diterapkan ketika terdapat buangan panas ke badan air. Suhu air ambien yang diukur langsung di lapangan bervariasi antara $24^{\circ} \mathrm{C}$ hingga $26,0^{\circ} \mathrm{C}$.

pH. Kisaran $\mathrm{pH}$ untuk semua lokasi air tanah adalah 5,0 -5,5. Nilai ini menun-jukkan indikasi keasaman yang tinggi hal ini disebabkan daerah kanal berada pada daerah rawa yang banyak mengan-dung asam-asam organik dan pada lahan gambut yang memiliki tigkat keasaman yang relalif tiggi karena didominasi oleh ion hidrogen.

Pembangunan kanal, mobilisasi peralatan dan bahan dan pembangunan log pond akan mengakibatkan masuknya bahan pencemar air ke dalam kanal, baik oleh tumpahan minyak dari sarana transportasi maupun peningkatan kekeruhan (TSS) akibat terjadinya abrasi dinding kanal karena terbentuknya gelombang kelvin dari pergerakan kapal angkut dan juga karena adanya kegiatan pengerukkan tanah oleh alat-alat berat.

Dampak tersebut persebarannya sangat luas pada seluruh kanal yang ada dan bersifat kumulatif dan membuat peluang pada kondisi gambut terjadinya pengeringan tak terbalikan (irreversible drying). Berlangsung selama operasi dan tidak dapat balik. Kegiatan pada tahap operasi, untuk penurunan permukaan air kanal sedalam 20-60 cm dari permukaan melalui kanal drainase dapat mengakibatkan tanah gambut pada ketebalan tertentu pada lapisan atas menjadi kering. Keringnya tanah gambut tersebut memberikan dampak ancaman pengeringan tak terbalikkan, amblesan dan kebakaran tanah gambut. Penurunan permukaan air kanal ini akan mengaki- batkan penurunan permukaan air tanah gambut.

\section{d. Fragmentasi Habitat}

Kegiatan pembangunan kanal akan berpengaruh terhadap habitat satwa liar dan diperkirakan akan menimbulkan fragmentasi habitat yang secara umum terjadi baik pada kualitas maupun kuantitas fungsional habitat. Perubahan yang bersifat mengurangi fungsi habitat satwa liar, terjadi akibat perubahan kondisi vegetasi alami (baik pada hutan sagu maupun hutan daratan/ non sagu), fragmentasi habitat oleh sistim kanal akan menimbulkan kebisingan sehingga membuat satwa liar akan berpindah/migrasi menjauhi lokasi proyek.

Hutan sagu alam, hutan daratan, mangrove dan sungai pada prinsipnya adalah sebuah ekosistem yang merupakan tempat penting bagi banyak jenis satwa liar seperti burung, mamalia, reptil dan amfibi. Satwa-satwa liar tersebut menggunakan secara spesifik bagian habitat yang ada seperti arboreal, teresterial, fusorial dan aquatik untuk membuat sarang (telur atau anak), mencari makanan maupun bermain. Satwa liar dengan kemampuan mobilitas yang tinggi seperti kebanyakan jenis burung, beberapa jenis mamalia besar seperti rusa, babi, dan kelompok Pteropodidae (codot dan kalong) dan beberapa jenis reptil mungkin akan melakukan migrasi ke habitat-habitat terdekat jika merasa terganggu.

Selain menyebabkan fragmentasi habitat, adanya kanal juga akan membentuk barier permanen yang akan mempengaruhi daerah jelajah satwa liar teresterial dan berakibat pada dampak turunan lainnya seperti persaingan sumber pakan dan tempat tinggal. Perubahan kondisi satwa liar dan habitatnya seperti dijelaskan di atas tidak dapat terhindarkan akibat kegiatan proyek. Namun Pembukaan kanal juga membuat 
habitat baru untuk beberapa jenis aves yang melakukan aktivitas di daerah kanal.

\section{Prediksi Jumlah Emisi Karbon Dioksida (diatas permukaan) Aki- bat Pembukaan Kanal}

Lokasi pembuatan kanal merupakan kawasan hutan sagu alam yang rapat secara alamiah. Kegiatan perusahaan membuat kanal selama tahap konstruksi sampai operasi mencakup kegiatan penebangan vegetasi hutan sagu alam pada areal rencana lokasi pembangunan kanal. Penebasan vegetasi pada areal rencana lokasi pembangunan kanal diprakirakan akan berdampak pada terbukanya tutupan lahan. Prediksi jumlah karbon dioksida ditunjukkan pada Tabel 4.

Pembukaan kanal yang meliputi pembuatan kanal dan pembukaan hutan sepanjang kiri dan atau kanan kanal hingga bulan juli 2013 seluas kurang lebih 82.35 ha. Melalui perhitungan perubahan penutupan lahan yang berubah fungsi diprediksi jumlah emisi karbon yang dilepas ke udara akibat pembukaan kanal sebesar 38,716.48 Ton CO2. Hal ini akan berakumulasi dari setiap penambahan atau pembukaan hutan untuk pembangunan kanal.

\section{Dugaan Cadangan Karbon (car- bon stock) Dalam Tanah (dibawah permukaan)}

Berdasarkan analisis pendugaan cadangan karbon dibawah tanah yaitu bobot isi (Bulk Density/BD) dan kandungan karbon $\left(\mathrm{C}_{\text {organik }}\right)$, yang di ambil sampel pada 5 lokasi pengamatan didapatkan bobot isi (Bulk Desity/BD) berkisar antara $0.58-1.22 \mathrm{~g} / \mathrm{cm}^{3}$ dan kandungan C-Organik berkisar antara $16.65-54.16 \%$, sehingga perhitungan cadangan karbon pada lapisan $0-30 \mathrm{~cm}$ seluas 1 ha sebesar 109 ton. Dengan ketebalan gambut lebih dari $30 \mathrm{~cm}$ akan terjadi akumulasi cadangan karbon dibawah tanah.

Bintoro (2010) menyatakan bobot isi gambut berkisar antara 0.010$0.20 \mathrm{~g} / \mathrm{cm}^{3}$ tergantung pada kematangannya, sedangkan bobot isi tanah mineral berkisar antara $1.2-1.8 / \mathrm{cm} 3$ tergantung pada teksturnya. Rendahnya bobot isi mencirikan rendahnya daya dukung lahan tersebut. Agus dan Susbiksa (2008) dalam Bintoro (2010) menambahkan bahwa volume gambut akan menyusut bila gambut didrainase, sehingga terjadi penurunan permukaan tanah (subsiden). Dekomposisi dan erosi mempercepat subsiden, dalam 2 tahun pertama setelah drainase, laju subsiden gambut mencapai $50 \mathrm{~cm}$. tahun-tahun berikutnya laju subsiden 2-6 cm/tahun tergantung kematangan gambut dan kedalaman saluran drainase (kanalisasi).

Andriesse (1988) dalam Bintoro (2010) menyatakan bahwa sifat kering tidak balik sangat erat kaitannya dengan bobot isi tanah (Bulk Density/BD). Keadaan kering tidak balik mudah terjadi di lahan gambut dengan tingkat kematangan fibrik yang memiliki bobot isi tanah lebih rendah dibandingkan dengan gam-but dengan tingkat kematangan hemiksaprik. Selain itu, dengan keadaan kering tanah gambut akan sangat mudah terbakar.

Kanal berfungsi sebagai sarana yang sangat penting dalam tata kelola air, untuk menunjang aktivitas produksi, sarana transportasi dan antisipasi kebakaran. Tata kelola air di lahan gambut sangat penting karena jika tanah gambut yang maupun menyimpan $90 \%$ air dari bobot mengalami kekeringan yang berlebihan, maka tanah gambut tersebut akan mengalami keadaan kering yang tidak terbalikan (irreversible drying). Sehingga dalam pemanfaatan sagu dan pembangunan kanal tidak diikuti oleh tata kelola air yang baik maka akan mengakibatkan degradasi gambut. 
Tabel 4. Prediksi jumlah karbon dioksida (diatas permukaan)

\begin{tabular}{ccccccc}
\hline \multirow{2}{*}{ No } & \multicolumn{2}{c}{ Tutupan } & $\begin{array}{c}\text { Perubahan } \\
\text { stock karbon }\end{array}$ & $\begin{array}{c}\text { Faktor } \\
\text { Emisi }\end{array}$ & $\begin{array}{c}\text { Aktivitas } \\
\text { Data }\end{array}$ & $\begin{array}{c}\text { Emision } \\
\text { Estimate }\end{array}$ \\
\cline { 2 - 7 } & Awal & Perubahan & $(\mathrm{C} /$ ha $)$ & $\left(\right.$ ton $\left.\mathrm{CO}_{2}\right)$ & $(\mathrm{Ha})$ & $\left(\right.$ ton/ $\left.\mathrm{CO}_{2}\right)$ \\
\hline 1. & HRP & TT & 200.2 & 734.13 & 21.25 & 15598.22 \\
2. & HRP & HRS & 107.86 & 395.52 & 53.05 & 20981.37 \\
3. & HLKP & HLKS & 42.1 & 154.38 & 6.32 & 975.71 \\
4. & HLKP & TT & 182 & 667.39 & 1.74 & 1161.18 \\
\hline & & & \multicolumn{5}{c}{ Total } & 82.35 & 38716.48 \\
\hline
\end{tabular}

Keterangan :

HRP : Hutan Rawa Primer, HRS : Hutan Rawa Sekunder, TT : Tanah Terbuka, HLKP : Hutan Lahan Kering Primer, HLKS : Hutan Lahan Kering Sekunder

\section{KESIMPULAN DAN SARAN Kesimpulan}

1. Areal IUPHHBK-HA PT. ANJ Agri Papua tergolong tipe hutan rawa yang didominasi oleh vegetasi Sagu (Metroxylon Spp.). Berdasarkan status kawasan tergolong dalam hutan produksi dan hutan produksi terbatas.

2. Potensi Pohon sagu berdiameter rata-rata $40 \mathrm{~cm}$ yang hilang akibat pembukaan kanal seluas $82.35 \mathrm{Ha}$ sebanyak 19.866 pohon dan yang telah masak tebang sebanyak 3.642 pohon, dengan kandungan pati sebesar 637.27 ton atau $637,265.48 \mathrm{Kg}$.

3. Perubahan biofisik-kimia lahan yang diakibatkan pada pembangunan kanal yaitu fragmentasi habitat, meningkatnya erosi dan longsoran dinding kanal, perubahan kualitas air terutama peningkatan Total Padatan Tersuspensi (TSS), yang berdampak lanjut pada meningkatnya kekeruhan, sedimentasi dan pendangkalan kanal.

4. Penambahan jumlah emisi karbon dioksida $\left(\mathrm{CO}_{2}\right)$ sebesar $38,716.48$ ton $\mathrm{CO}_{2}$, pada luasan konstruksi seluas 82.35 ha dan diduga akan meningkat sejalan dengan peningkatan luas kanal.
5. Bobot isi (Bulk Desity) tanah berkisar antara $0.58-1.22 \mathrm{~g} / \mathrm{cm} 3$ dan kandungan C-Organik berkisar antara 16.65 - $54.16 \%$, sehingga cadangan karbon pada lapisan $0-30 \mathrm{~cm}$ sebesar 109 ton/ha.

\section{Saran}

1. Pihak Perusahaan IUPHHBKHA PT. ANJ Agri Papua wajib merancang kontruksi kanal yang efektif dalam tata kelola air, meningkatkan konservasi dan pembukaan lahan minimal.

2. Untuk mengantisipasi suatu keadaan kering yang tidak terbalikan (irreversible drying) dan kebakaran hutan perlu dilakukan monitoring air dengan menggunakan alat water level, piezometer dan pintu air.

3. Kontruksi kanal dibuat berbentuk "V" bukan "U" sehingga dapat mengurangi erosi dan abrasi atau longsoran.

4. Perlu dilakukan penelitian model arah dan bentuk kontruksi kanal yang mampu meminimalisasi perubahan biofisik lahan di areal hutan sagu.

5. Perlu penelitian lebih lanjut untuk untuk mengetahui persediaan karbon dan emisi $\mathrm{CO}_{2}$ 
pada ekosistem hutan sagu di Papua.

\section{DAFTAR PUSTAKA}

Agus, F, K. Hariah dan Anny Mulyani. 2011. Petunjuk Praktis : Pengukuran Cadangan Karbon Tanah Gambut. Word Agroforestry Centre-ICRAF, SEA Regional Office dan Balai Besar Penelitian dan Pengembangan Sumberdaya Lahan Pertanian (BBS DLP). Bogor

Anonim. 1976. Vademecum Kehutanan Indonesia. Direktorat Jenderal Kehutanan Departemen Pertanian

Anonim. 2001. Peraturan Pemerintah Nomor 82 tahun 2001 tentang Persyaratan Kualitas Air.

Anonim. 2002. Keputusan Menteri Kesehatan RI Nomor 907/MEN KES/SK/VII tahun 2002 tentang Syarat-Syarat Dan Pe-ngawasan Kualitas Air Minum.

Anonim. 2010. Dokumen Analisis Dampak Lingkungan PT. Austindo Nusanara Jaya Agri Papua. Anonim. 2012. Peraturan Pemerintah Nomor 27 Tahun 2012 tentang Izin Lingkungan.

Asdak Chay. 2004, Hidrologi dan Pengelolaan Daerah Aliran Sungai. Gadjah Mada University Press. Yogyakarta.

Badan Stradarisasi Nasional. 2004. SNI. 06-6989.3-2004. Air Dan Air Limbah - Bagian 3: Cara Uji Padatan Tersuspensi Total (Total Suspended Solid, TSS) Secara Gravimetri. Badan isasi Nasional.

Badan Stradarisasi Nasional. 2005. SNI. 06-6989.25-2005. Air Dan Air Limbah - Bagian 25: Cara Uji Kekeruhan Dengan Nefelometer. Badan Stradarisasi Nasional.
Badan Stradarisasi Nasional. 2005.SNI. 06-6989.26-2005. Air Dan Air Limbah - Bagian 26: Cara Uji Padatan Total Secara Gravimetri.

Badan Stradarisasi Nasional. 2005. SNI. 06-6989.27-2005. Air Dan Air Limbah - Bagian 27 : Cara Uji Padatan Total Total Secara Gravimetri. Badan Stradarisasi Nasional.

Badan Stradarisasi Nasional. SNI. 6989.57:2008. Air Dan Air Limbah - Bagian 57 : Metode Pengambilan Contoh Air Permukaan. Badan Stradarisasi Nasional.

Bappenas. 2012. Modul Pelatihan Inventarisasi Emisi Gas Rumah Kaca dan Perhitungan BAU Baseline

Bidang Berbasis Lahan (Pertanian, Kehutanan dan Lahan Gambut) Bintoro, H. M. H. 2008. Bercocok Tanam Sagu. IPB Press. Bogor.

Bintoro, H. M. H, H.M. Yanuar J. Purwanto dam Shandra Amarlis. 2010. Sagu Di Lahan Gambut. IPB Press. Bogor

Hairiah, K., Ekadinata A, Sari RR, Rahayu S.2011. Petunjuk Praktis Edisi Kedua: Pengukuran Cadangan Karbon di Tingkat Lahan ke Bentang Lahan. Word Agroforestry Centre, ICRAF SEA Regional Office of Brawi-jaya. Malang.

IPCC. 2006. Guidelines for National Green House Gas InventoriesVolume 4: Agriculture, Land Uses

Forestry(GL-AFOLU). http://www.pccnggip.iges.or.jp/public/2006g/v ol4.html. (10 Januari 2006)

Kanro, M.J, A. Rouw, A. Widjono, Syamsudin, Amisnaipa dan Atekan. 2003. 'Tanaman Sagu dan 
Pemanfaatannya di Provinsi Papua", Litbang Pertanian, Vol 22, no. 3, hal. 116-124. Kusmana, C. 1997 Metode Survey Vegetasi. Institut Pertanian Bogor. Bogor

Masripatin, N. et al. 2010a. Pedoman Pengukuran Karbon untuk Mendukung Penerapan REDD+ di Indonesia. Proyek Climate Change, Forest and Peatlands in Indonesia. Pusat Penelitian dan Pengembangan Perubahan Iklim dan Kebijakan. Bogor

Masripatin, N. et al. 2010b. Cadangan Karbon pada Berbegai Tipe Hutan dan Jenis Tanaman. Proyek Climate Change, Forest and Peatlands in Indonesia. Pusat Penelitian dan Pengem-bangan Perubahan Iklim dan Kebijakan. Bogor

Prihatman, K (ed.) 2000. Sistem Informasi Manajemen Pembangunan Kehutanan. Kantor Deputi

Menegristek Bidang Pendayagunaan dan Pemasyarakatan. Jakarta

Rahayu Subekti, Rudi Harto Widodo, Meine van Noordwijk, Indra Surya, Bruno Verbist. 2009.

Monitoring Air Di Daerah Aliran Sungai. Word Agroforestry Centre Bogor

Suratmo, M. J. 1993. Analisis Mengenai Dampak Lingkungan. Gadjah Mada University. Press. Yogyakarta

Suryadiputera dan Adi Jaya. 2004. Petunjuk Lapangan : Pendugaan Cadangan Carbon pada Lahan Gambut. Proyek Climate Change, Forest and Peatlands in Indonesia. Weetlands Iternational - Indonesia Programmed an Wildlife Habitat Canada. Bogor Suryadiputra, I.N.N., Alue Dohong, Roh, S.B. Waspodo, Lili Muslihat, Irwansyah R. Lubis. Ferry Hasudungan, dan Iwan T.C. Wi- bisono. 2005. Panduan Penyekat Parit dan Saluran di Lahan Gabut Bersama Masyarakat. Proyek Climate Change, Forest and Peatlands in Indonesia. Weetlands Iternational - Indonesia Programmed an Wildlife Habitat Canada. Bogor. 